\title{
Small Clause complemento: caracterização e seleção
}

\author{
Complement Small Clause: properties and selection
}

Andréia de Fátima Rutiquewiski Gomes Universidade Tecnológica Federal do Paraná - UTFPR

Maria José Foltran

Universidade Federal do Paraná - UFPR

$\mathrm{CNPq}$

Resumo

Este artigo discute as propriedades distribucionais das small clauses complementos, diferenciando-as dos predicados secundários. Realiza então uma análise dos verbos judicativos, como considerar, julgar, etc., com o objetivo de verificar quais desses verbos são capazes de selecionar small clauses complementos.

\section{Palavras-chave}

Small clause complemento, Complementação, Verbos judicativos

\section{Abstract}

This paper aims at establishing syntactic and semantic characteristics of complement small clauses. Based on the established creteria, we analyse verbs of judgement, like consider, in order to identify whether they select the small clause structure.

\section{Keywords}

Complement small clause, Complementation, Verbs of judgement 


\section{Considerações Iniciais ${ }^{1}$}

N

este artigo, realizamos uma análise de alguns verbos judicativos quanto à possibilidade de apresentarem small clauses como complementos. Entendemos como verbos judicativos aqueles que selecionam um complemento em que se atribui a alguém ou alguma coisa um julgamento, como considerar, julgar, achar, entre outros. O complemento, portanto, apresenta uma estrutura complexa, em forma de uma oração sem tempo. Estruturas desse tipo são chamadas na literatura de small clauses. As small clauses, ${ }^{2}$ segundo Rothstein (1995, 2001), são casos de predicação primária e diferem das construções denominadas predicados secundários. Numa predicação primária, sujeito e predicado estão em c-comando mútuo, formam um constituinte juntos e o sujeito não é tematicamente licenciado fora da relação de predicação em que ocorre. A hipótese da autora é que instâncias de predicação primária formam sentenças (IPs) ou então small clauses como em (1):

(1) a. Considero Maria inteligente.

b. Maria parece inteligente.

Para Rothstein (1995), tanto os complementos de verbos de Marcação Excepcional de Caso (ECM - Exceptional Case Marking) como considerar (1a) como os de verbos de alçamento (1b) são casos de predicação primária e, portanto, são small clauses. ${ }^{3}$ A diferença entre essas duas estruturas é que, em (1a), sujeito e predicativo permanecem juntos e, em (1b), separam-se. Em (1a), o verbo considerar seleciona todo o complemento oracional Maria inteligente, ao qual atribui papel- $\theta$ interno. $O$ verbo atribui papel- $\theta$ a todo o constituinte oracional, porque é esse o seu complemento - Maria é sujeito desse sintagma oracional e não complemento do verbo considerar. Maria e o predicado inteligente podem ficar juntos em (1a) porque o Caso (Acusativo) de Maria está disponível através de ECM pelo verbo matriz. No caso da sentença Maria 
parece inteligente (1b'), o verbo inacusativo ${ }^{4}$ parece está selecionando uma small clause como complemento: Parece [ $_{\mathrm{SC}}$ Maria inteligente]. É o AP inteligente, e não o verbo, que atribui papel temático ao sujeito da small clause Maria. Isso equivale a dizer que Maria é um argumento de inteligente e não de parece. Como na posição de argumento interno de verbo inacusativo Maria não tem Caso (já que parece é incapaz de atribuir Caso Acusativo e o adjetivo não é núcleo atribuidor de Caso), este elemento é alçado para Spec de IP em busca de Caso (Nominativo) e o predicado inteligente é abandonado in situ. É por esse motivo que, em complemento de verbo de alçamento como parecer, o sujeito e o predicado da small clause não podem permanecer juntos.

Diferentemente da predicação primária, a predicação secundária não forma um constituinte e ocorre quando o sujeito é um argumento também $\theta$-marcado numa relação fora da relação de predicação secundária, ou seja, o sujeito de um predicado secundário recebe papel temático duas vezes. Por exemplo, na sentença em (2), o suco recebe papel temático de tomou e de gelado, pois gelado também é um predicado.

(2) Maria tomou o suco gelado.

A sentença em (2) apresenta um predicado secundário orientado para o objeto, pois o adjetivo é predicado do objeto direto. Já uma estrutura como Maria saiu do baile irritada contém um caso de predicado secundário orientado para o sujeito, porque o adjetivo predicativo relaciona-se com o sujeito da oração. Há, ainda, o predicado resultativo, como em Ela cortou o cabelo curto. Este predicado descreve o estado final do objeto direto. ${ }^{5}$

Rothstein reconhece que sua análise dos predicados secundários viola $\mathrm{o}$ critério- $\theta$ proposto por Chomsky (1981). Esse critério propõe que todo papel- $\theta$ deve ser atribuído a um e somente um argumento e que todo argumento deve receber um e somente um papel- $\theta$. Para resolver essa violação, Rothstein adota a proposta de $\operatorname{Schein}(1995$, p.50), a qual propõe que cada argumento recebe um papel- $\theta$, e cada papel- $\theta$ é atribuído para um e somente um argumento. Assim, segundo Schein, um argumento não pode receber mais de um papel- $\theta$ do mesmo núcleo, o que viabiliza a definição de predicado secundário de Rothstein.

Com esses pressupostos, Rothstein (1995) argumenta que há dois tipos de estrutura nos dados (1-2). Os complementos verbais que formam um único constituinte são instâncias de predicação primária (como é o caso das small 
clauses: Considero Maria inteligente, Maria parece inteligente). Já os que não formam são considerados casos de predicação secundária (como em Maria tomou o suco gelado, em que tomou seleciona apenas o seu objeto).

Dentre os dois exemplos de small clauses apresentados em (1), nosso interesse está voltado apenas para construções como em (1a), ou seja, para as small clauses complementos de verbos ECM como considerar. É importante destacar que, nestas estruturas, os predicados encaixados podem ser de categoria adjetival (Considero a tarefa difícil), nominal (Considero João um amigo) ou preposicional (Considero essa hipótese de grande valia).

Para o desenvolvimento deste trabalho, dividimos a temática em três partes. Na seção 1, discutimos os testes de diferenciação entre predicados primários e secundários propostos por Rothstein (1995) e verificamos quais deles podem ser aplicados às estruturas do português. Na seção 2 , realizamos uma análise dos principais verbos pertencentes à mesma classe do verbo considerar (os verbos judicativos) quanto às suas propriedades de subcategorização. Esta análise baseia-se em critérios estabelecidos pela literatura. Finalmente, tecemos algumas considerações a respeito das principais conclusões obtidas.

\section{Testes de caracterização de small clauses complementos e predicados secundários propostos em Rothstein}

Rothstein (1995) fornece evidências de que a estrutura dos complementos de verbos ECM e a dos predicados secundários são diferentes. Essa diferença pode ser atestada por meio dos testes de paráfrase com cópula ser, inserção de advérbios, efeitos da condição de sujeito, acarretamento e coordenação, que indicam se os complementos dos verbos analisados formam ou não um único constituinte (ou seja, se são ou não small clauses). Quando dizemos que formam um único constituinte, estamos afirmando que há um nódulo na estrutura sintática que combina o nome e o adjetivo predicativo somente, ou seja, o nódulo $\mathrm{SC}^{6}$ no diagrama a seguir. ${ }^{7}$ 


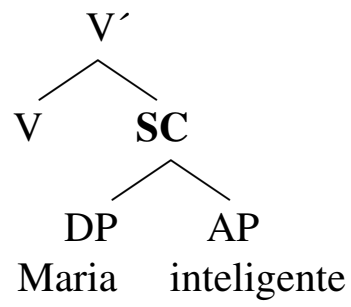

Já na estrutura que (2) supõe, o suco gelado não é argumento de tomar e não há nenhum ponto em que o suco gelado vai formar um único constituinte, como se pode ver abaixo, numa estrutura com PRO proposta por Stowell (1983).

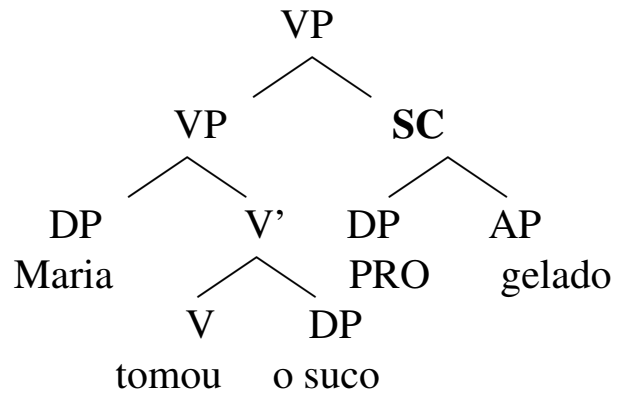

No decorrer da pesquisa, pudemos verificar que esses testes são mais eficazes para distinção entre as small clauses complementos de verbos como considerar (e não para complementos de verbos de alçamento) e os predicados secundários. Por esse motivo, alguns dos testes discutidos aqui são utilizados também em nossa análise dos verbos judicativos, apresentada na próxima seção.

A primeira evidência para diferenciar uma small clause complemento de um predicado secundário que Rothstein (1995) apresenta é a possibilidade de a small clause complemento poder aparecer parafraseada por estruturas com a cópula (3):

(3) a. Considero a situação complicada.

b. Considero ser a situação complicada. ${ }^{8}$

c. *Considero a situação ser complicada. 
Podemos observar que, no português, a cópula deve aparecer logo após o verbo da sentença matriz, como mostra o exemplo em (3b). A sentença com a cópula após o sujeito da small clause é agramatical (3c).

Ao contrário das small clauses complementos, os predicados secundários não admitem a construção com a cópula, como indicam as sentenças em (4):

a. Maria tomou o chá gelado.

b.*Maria tomou ser o chá gelado.

c. *Maria tomou o chá ser gelado.

A inserção dos advérbios, segundo Rothstein (1995), constitui um outro teste que pode ajudar a diferenciar a small clause complemento do predicado secundário. Os advérbios têm alcance apenas no constituinte em que ocorrem. Geralmente, quando seguem um objeto, os advérbios modificam o verbo que rege esse objeto. O que acontece é que, em complementos de verbos como considerar, os advérbios modificam o predicado complemento. Assim, o fato de o advérbio não poder modificar o verbo principal, como em (5), é uma evidência de que há uma small clause complemento e não uma predicação secundária, já que, nesta última, o predicado não forma um constituinte com o seu sujeito.

(5) Eu considero [Maria frequentemente inconveniente].

$\mathrm{O}$ advérbio frequentemente refere-se apenas à inconveniência de Maria, portanto seu alcance restringe-se à small clause, não modificando o verbo matriz. $\mathrm{O}$ fato de o advérbio não ter alcance sobre o verbo matriz é uma prova de que ele está inserido numa small clause complemento. Isso se comprova com a sentença em (6), que admite dois advérbios, um modificando a small clause complemento (frequentemente) e outro (raramente), a sentença matriz:

(6) Eu raramente considero as pessoas frequentemente inconvenientes. 9

Já em (7), ao contrário de (5), o advérbio frequentemente pode ter alcance tanto sobre o verbo matriz como sobre o adjetivo predicativo. Frequentemente pode referir-se tanto ao fato de a carne estar crua, quanto ao fato de comer carne. Isso demonstra que o predicado secundário em (7) não forma um constituinte com seu sujeito: 
(7) Ela come carne frequentemente crua.

Essa hipótese é reforçada pela sentença (8), que contém dois advérbios, um modificando o verbo matriz e o outro, o complemento. Este último é agramatical. O predicado secundário compõe-se com o predicado primário. Isso impossibilita que os advérbios modifiquem os dois separadamente.

(8) *Ela frequentemente bebia o café raramente frio.

Outro teste aplicado por Rosthstein (1995) para mostrar que a small clause forma um único constituinte vem de Kayne (1984). Este autor fala sobre os efeitos das condições de sujeito: nada se pode extrair a partir da posição de sujeito. Esse efeito ocorre, conforme Kayne, devido à condição de conexidade (nada pode ser extraído de um constituinte que nãoé canonicamente regido). Um NP é canonicamente regido apenas pela categoria que o precede. Vejamos a extração em (9):

*Who ${ }_{\mathrm{i}}$ do you consider the sister of $\mathrm{t}_{\mathrm{i}}$ very smart?

A sentença (9) mostra que os elementos a partir dos quais houve extração apresentam efeitos da condição de sujeito. Isso significa que o NP a partir do qual houve a extração em (9) comporta-se mais como sujeito do que como objeto devido ao tipo de extração que permite. Assim, (9) contém uma small clause que não permite a extração a partir de seu sujeito.

Rothstein (1995) contrasta sentenças como (9) com predicados secundários (10):

(10) Who did you meet the sister of $\mathrm{t}_{\mathrm{i}}$ drunk?

Para a autora, o fato de sentenças como (10) serem gramaticais demonstra que o constituinte do qual se está extraindo nãoé sujeito e, por isso, não pode estar formando small clause complemento.

Vejamos, agora, no português, como se comportam o predicado secundário e a small clause complemento quanto à possibilidade de extração. A sentença (11) contém um exemplo de predicado secundário:

(11) a. Você $\left[_{\mathrm{VP}}\right.$ encontrou [ ${ }_{\mathrm{DP}}$ a irmã de quem bêbada]]?

b. De quem ${ }_{i}$ você encontrou a irmã $t_{i}$ bêbada? 
Por ser um predicado secundário, a extração, segundo Rothstein, deve ser possível, já que não está se extraindo a partir da posição de sujeito. Embora a aceitabilidade de (11b) entre os falantes pareça variar, julgamos que é uma sentença gramatical.

Em (12), temos uma small clause complemento, de onde se espera não ser possível a extração, já que sujeitos de small clauses apresentam efeitos da condição de sujeito.

(12) a. Você $\left[_{V P}\right.$ considera $\left[_{S C}\left[{ }_{S U J}\right.\right.$ a irmã de quem $]\left[_{\mathrm{PRED}}\right.$ inteligente $\left.\left.]\right]\right]$ ?

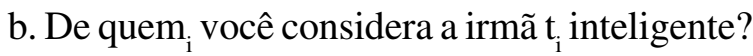

Não há consenso sobre a gramaticalidade de (12b). Para Rothstein (1995), a sentença (12b) deveria ser agramatical, porém não podemos afirmar isso com relação às sentenças com small clause complemento no português, pois a sentença (13), outra small clause, também não traz dados conclusivos. Os julgamentos de (12b) e (13) diferem tanto quanto os de (11b).

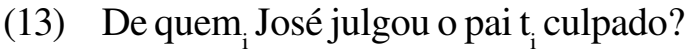

Dessa forma, concluímos que esse teste não pode ser considerado um meio de diferenciar small clause complemento e predicado secundário no português, já que as sentenças com extração a partir do sujeito não produzem o efeito desejado.

A próxima evidência de que a estrutura da small clause complemento forma um constituinte diz respeito à noção de acarretamento. Essa noção é importante porque demonstra o que o verbo matriz está selecionando como seu complemento. Em (14a), por exemplo, podemos verificar que o verbo considerar está selecionando todo o complemento a prova difícil e não apenas a prova. Isso é comprovado pela ausência de acarretamento entre (14a) e (14b), pois em (14b) não podemos ter a mesma interpretação de (14a). Assim, a indicação de que o complemento em (14a) é uma small clause é a falta de um vínculo entre (14a) e (14b), demonstrando que em (14a) o verbo seleciona o predicado difícil e também seu argumento a prova, ou seja, a small clause. Logo, em (14a), temos uma small clause complemento.

(14) a. Eu considerei a prova difícil.

b. \#Eu considerei a prova. 
Em (15) a estrutura é diferente, pois não há formação de small clause complemento (não há um único constituinte em o chá gelado). A sentença (15a) acarreta (15b). $\mathrm{O}$ fato de tomar o chá gelado acarreta que ele tomou o chá. Tal fato sugere que (15a) contém um predicado secundário.

(15) a. Ele tomou o chá gelado.

b. Ele tomou o chá.

O último teste para a comprovação da estrutura da small clause complemento discutido por Rothstein (1995) é a coordenação. Em (16a), percebemos a impossibilidade de coordenar um NP com uma small clause complemento. A sentença (16a) mostra que não é possível interpretar que o predicado adjetivo pertença apenas ao segundo NP na small clause, conforme a estrutura em (16b).

(16) a. Eu considerei a indagação e a solução errada.

b. Eu considerei [a indagação] e [ ${ }_{\mathrm{SC}}$ a solução errada].

A única leitura aceitável de (16a) é considerar a indagação e a solução como um sujeito ligado pela conjunção coordenada $e$ do predicado errada. Não é aceitável a leitura em que ao predicado pertença somente o segundo NP, numa leitura equivalente à eu considerei a indagação, e eu considerei a solução errada. Já a sentença (17) revela que, em predicados adjuntos, isso é possível: (17a) é equivalente a (17b).

(17) a. Ele tomou o café e o chá gelado.

b. Ele tomou o café e ele tomou chá gelado.

Nas sentenças em (18), o verbo toma dois objetos diretos, podendo, inclusive, o segundo objeto, somente, aparecer com um predicado secundário. Isso é confirmado pela possibilidade de alteração na ordem da sentença, como mostra (18b):

(18) a. Ele tomou o café e o chá gelado.

b. Ele tomou o chá gelado e o café.

Os argumentos de Rothstein (1995) discutidos aqui indicam que, em uma small clause, sujeito e predicado formam um único constituinte ao contrário do 
que acontece em uma predicação secundária. Fica assim estabelecido que a small clause em complementos de verbos ECM, como considerar, constitui uma predicação primária.

\section{A seleção de small clauses complementos: uma análise dos verbos judicativos}

Verbos como considerar, julgar, declarar, achar, supor, crer, reconhecer, acreditar pertencem à classe dos verbos judicativos. Essa classe de verbos é utilizada quando o falante deseja expressar julgamentos, opiniões e avaliações acerca de fatos, objetos, pessoas, lugares, etc. Numa primeira observação, tudo sugere que os verbos pertencentes a essa classe parecem permitir a ocorrência de small clauses complementos. Assim, nesta seção, nosso objetivo consiste em verificar as propriedades de subcategorização desses verbos, ou seja, se selecionam ou não as estruturas em foco aqui.

\subsection{Critérios}

Nem todos os testes propostos por Rothstein (1995) são capazes de caracterizar a estrutura de uma small clause no português (como é o caso, por exemplo, do teste relacionado aos efeitos da condição de sujeito). A paráfrase com cópula ser, a inserção de advérbios e a noção de acarretamento mostraramse eficazes para individualizar a estrutura das small clauses e podem, portanto, também contribuir para mostrar quais verbos podem selecionar esse tipo de construção. Assim, utilizamos essas três evidências como critérios para a nossa análise dos verbos judicativos do português. Acrescentamos também outro critério que aparece na literatura como caracterizador da estrutura de uma small clause complemento: a possibilidade de apresentar um DP na posição de predicado (Considero o João um atleta). Percebemos também que em muitos casos a small clause pode ser parafraseada por uma subordinada encaixada. Observamos, desse modo, a possibilidade de o verbo poder selecionar, além da small clause, uma sentença com flexão. Vejamos todos os critérios na ordem em que são considerados na análise e estabeleçamos brevemente o significado que cada um deles tem. 
i) A noção de acarretamento - o acarretamento mostra o que o verbo matriz está selecionando como seu complemento. Em Considero Maria inteligente, o verbo considerar está selecionando todo o complemento Maria inteligente e não apenas Maria. A evidência disso é que não há acarretamento entre Considero Maria inteligente e Considero Maria (considero Maria inteligente não acarreta que considero a Maria). Como não há acarretamento entre as duas sentenças (inteligente não é um adjunto de Maria), há uma small clause complemento. Em um predicado secundário, o verbo não seleciona toda a proposição, mas apenas seu objeto direto, como mostra a sentença Encontrei o livro aberto. Nesse caso, encontrar o livro aberto acarreta encontrar o livro, o que mostra que aberto é um adjunto de livro e que, portanto, livro aberto não constitui uma small clause.

(ii) Ainserção de advérbios - os advérbios têm alcance apenas no constituinte em que ocorrem. Quando inseridos num predicado encaixado, se os advérbios não tiverem alcance sobre a sentença matriz, estão numa estrutura que forma um único constituinte, ou seja, numa small clause. Em $O$ João acha os políticos geralmente corruptos, o advérbio geralmente modifica apenas o predicado da small clause, não tendo alcance sobre a sentença matriz. Prova disso é que podemos verificar que sentença com complemento small clause aceita a inclusão de dois advérbios ( $O$ João raramente acha os políticos geralmente corruptos). Tal fato não é possível em um predicado secundário (*Ela frequentemente bebia o café raramente frio), já que o advérbio inserido nessa estrutura tem alcance também sobre a sentença matriz.

(iii) Oração encaixada com tempo finito - as small clauses podem aparecer com uma oração encaixada com tempo finito (Considero que Maria é inteligente). Isso, porém, não acontece com as construções de predicação secundária ( $*$ Encontrei que o livro está aberto).

(iv) Paráfrase com cópula ser - as small clauses complementos permitem paráfrase com cópula (Julgo ser o réu inocente), ao contrário dos predicados secundários ( ${ }^{*}$ Encontrei estar o livro aberto) ${ }^{10}$.

(v) Predicado DP - as small clauses complementos aceitam predicados DPs, como em Considero Maria uma doida. Um predicado secundário, no entanto, não permite essa possibilidade (*Encontrei Pedro um gênio). 


\subsection{Análise dos verbos}

Iniciamos a análise com o verbo considerar que, conforme a literatura, parece ser o representante típico dos verbos que selecionam small clause complemento.

(19) a. Considero a Maria complicada.

b. \# Considero a Maria.

c. Raramente considero as mulheres frequentemente complicadas.

d. Considero que a Maria é complicada.

e. Considero ser a Maria complicada.

f. Considero a Maria uma amiga.

Em(19a-b), podemos perceber o que é selecionado pelo verbo considerar. Este verbo seleciona todo o complemento proposicional a Maria complicada. Como evidência, temos a noção de acarretamento. A retirada do predicado da small clause complemento, como demonstra (19b), ocasiona mudança de interpretação. A sentença (19b) não pode ser interpretada no mesmo sentido de (19a). O fato de considerar a Maria complicada não quer dizer que considera a Maria. A sentença (19a) não acarreta (19b). Isso indica que não se pode considerar o DP a Maria como objeto do verbo considerar, mas sim como sujeito da small clause. Como vimos, os advérbios têm alcance apenas no constituinte em que ocorrem. Assim, se um advérbio localizado em um complemento não tem alcance sobre o verbo principal, esse complemento é considerado uma small clause complemento. Pela sentença (19c), verificamos que o advérbio frequentemente está inserido na small clause, pois tem alcance apenas dentro dela. Frequentemente refere-se apenas ao predicado adjetivo complicadas. Prova disso é o fato de a sentença aceitar outro advérbio, neste caso, raramente, modificando o verbo da sentença matriz. A presença dos dois advérbios na sentença comprova que considerar está selecionando uma small clause complemento. A sentença (19d) mostra que o verbo considerar aceita uma oração encaixada com tempo finito (seleciona o CP: que a Maria é complicada). A sentença (19e) demonstra que a small clause complemento pode ser parafraseada pela cópula ser. Em (19f), verificamos que o verbo considerar aceita uma small clause nominal, ou seja, a small clause selecionada pelo verbo considerar aceita um DP (uma amiga) na posição de predicado. Através desses testes, podemos afirmar que o verbo considerar é 
realmente o verbo típico para a seleção de small clause complemento no português do Brasil.

Se aceitamos esses critérios como indicadores da existência de uma small clause complemento, podemos agora estender essa mesma análise aos outros verbos pertencentes a essa mesma classe.

Verbo declarar

(20) a. O juiz declara o réu culpado.

b. ${ }^{*}$ juiz declara o réu.

c. O juiz geralmente declara os réus frequentemente culpados.

d. O juiz declara que o réu é culpado.

e. O juiz declara ser o réu culpado.

f. O juiz declara o réu um herói.

Declarar pode ser compreendido, na sentença (20a), como pronunciou, deu a conhecer. Vejamos o que os testes sugerem: pelas sentenças (20a) e (20b), é possível verificar que o réu não é o objeto do verbo declarar, pois, se eliminarmos o predicado adjetivo da small clause culpado, a sentença tornase agramatical (e, portanto, não temos acarretamento). Esse fato deixa claro que o verbo declarar seleciona um complemento proposicional, uma small clause complemento (réu culpado). A sentença (20) aceita a inclusão de dois advérbios, um (frequentemente) que modifica só a small clause e outro que modifica a sentença matriz (geralmente), como verificamos em (20c). Isso mostra que o advérbio frequentemente está inserido numa small clause complemento, pois só tem alcance dentro dela. Com a sentença (20d), vemos que o verbo declarar aceita oração encaixada com tempo finito. Com relação à paráfrase com a cópula ser, verificamos que o verbo declarar também aceita a inserção, como indica (20e). A sentença (20f) mostra a possibilidade de um predicado DP (um herói) na small clause selecionada pelo verbo declarar. Os testes realizados em (20) indicam que o verbo declarar seleciona small clause complemento. 


\section{Verbo supor}

(21) a. João supunha José inteligente.

b.* João supunha José.

c. João raramente supunha as pessoas frequentemente inteligentes.

d. João supunha que José é inteligente.

e. João supunha ser José inteligente.

f. João supunha José um amigo.

O verbo supor em (21) pode ser compreendido no sentido de estabelecer uma hipótese, imaginar, conjeturar, presumir. Em (21a-b), temos o primeiro indício de que o verbo supor pode selecionar small clause, pois (21b) é agramatical. Isso mostra que supor em (21a) seleciona todo o complemento José inteligente. $\mathrm{O}$ advérbio frequentemente modifica apenas o constituinte em que está inserido. Prova disso é que a sentença aceita a inserção do advérbio raramente modificando o verbo matriz (21c). Supor aceita oração encaixada com tempo finito, como mostra a sentença (21d). A sentença (21e) apresenta a possibilidade da paráfrase com a cópula ser. Em (21f), verificamos que o verbo supor pode selecionar uma small clause com um DP como predicado (um amigo). Com esses resultados, é possível concluir que o verbo supor é capaz de selecionar small clause complemento.

Verbo achar

(22) a. Maria acha os homens inteligentes.

b. \#Maria acha os homens.

c. Maria geralmente acha os homens frequentemente inteligentes.

d. Maria acha que os homens são inteligentes.

e. Maria acha serem os homens inteligentes.

f. Maria acha aquele homem um tolo.

O verbo achar, no sentido de considerar, seleciona small clause complemento. Achar, no sentido relevante aqui, passa por todos os testes que confirmam a seleção de small clause complemento. A sentença (22a) não acarreta (22b). O fato de Maria achar os homens inteligentes não acarreta que Maria acha os homens. $\mathrm{O}$ advérbio frequentemente não tem alcance sobre o verbo matriz (achar), fato que se comprova pela possibilidade da ocorrência 
de outro advérbio (geralmente) modificando tal verbo. O verbo achar também aceita oração encaixada com tempo finito (que os homens são inteligentes) $\mathrm{e}$ paráfrase com cópula ser (Maria acha serem os homens inteligentes). A sentença (22f) mostra que a small clause selecionada pelo verbo achar aceita um DP na posição de predicado (Maria acha aquele homem um tolo).

Verbo Julgar

(23) a. Pedro julga o atleta inocente.

b. Pedro julga o atleta.

c. Pedro raramente julga os atletas frequentemente inocentes.

d. Pedro julga que o atleta é inocente.

e. Pedro julga ser o atleta inocente.

f. Pedro julga o atleta uma potência.

O verbo julgar em (23) pode ser compreendido como considerar ou decidir como juiz. Os dados em (23c-f) indicam que este verbo é capaz de selecionar small clauses complementos, embora o teste em ( $23 \mathrm{~b}$ - acarretamento) não favoreça essa conclusão. Isso porque, segundo os critérios de identificação de small clause estabelecidos no início desta análise, não poderia existir acarretamento entre (23a) e (23b). No entanto, o fato de Pedro julgar o atleta inocente acarreta que Pedro julgou o atleta. Isso também acontece em outras sentenças com o verbo julgar: O juizjulgou o réu culpado, acarreta que o juiz julgou o réu. Maria julgou João um tolo, acarreta que Maria julgou João. $\mathrm{O}$ verbo julgar parece sempre apresentar essa idiossincrasia. Passemos agora aos outros testes em (23), que confirmam a possibilidade de seleção de small clauses complementos pelo verbo julgar: a sentença (23c) contém dois advérbios, mostrando que o advérbio frequentemente tem alcance apenas no constituinte complemento do verbo julgar. Frequentemente não tem alcance sobre o verbo matriz, apenas raramente refere-se ao verbo julgar. Isso deixa claro que frequentemente está inserido numa small clause complemento. Em (23d), verificamos que julgar pode selecionar $\mathrm{CP}$ (que o atleta é inocente) e, em (23e), podemos observar que este verbo permite construção com cópula ser (Pedrojulga ser o atleta inocente). O último teste em (23) mostra que o predicado da sentença encaixada pode ser constituído por DP (Pedro julga o atleta uma potência). Consideramos, assim, que julgar pode selecionar small clause complemento. 


\section{Verbo acreditar}

(24) a.*João acredita o médico inocente.

b.* João acredita o médico.

c. *João raramente acredita os médicos frequentemente inocentes.

d. João acredita que o médico é inocente.

e.?João acredita ser o médico inocente.

f. *João acredita o médico um amigo.

Como indicam as sentenças em (24), o verbo acreditar não seleciona small clause complemento. A forma possível de se expressar a ideia do verbo acreditar com uma opinião (inocente) seria com este verbo selecionando um $\mathrm{CP}$ (João acredita que o médico é inocente). O verbo acreditar, no sentido pretendido pelas sentenças em (24), significa considerar, ter na conta, achar. Encontramos, porém, encontramos a sentença (25a) no Dicionário Aurélio (2004, p. 41):

(25) a. Não o acredito capaz de magnanimidades.

b. ?Não acredito o João capaz de magnanimidades.

c. ?Não acredito ele capaz de magnanimidades.

Em (25a), temos o verbo acreditar selecionando uma small clause complemento. O sujeito da small clause é a forma pronominalizada $o$. Essa forma pronominalizada é uma prova de que o verbo acreditar atribui Caso Acusativo excepcionalmente ao sujeito da small clause. Substituindo o pronome $o$ de (25a), o resultado é (25b), que se mostra pouco aceitável. Isso também acontece em (25c), que apresenta o estágio esperado de transição do pronome oblíquo $o$ para o pessoal ele. O uso do pronome oblíquo $o$ no lugar do sujeito da small clause nos leva a estruturas do tipo (26) e (27):

(26) João o acredita inocente.

(27) Maria o acredita culpado dos fatos.

Temos, no entanto, de lembrar que formas pronominalizadas como as mostradas acima não são mais utilizadas no português brasileiro. Sentenças como (25a), (26) e (27) são próprias de um registro bastante formal e não correspondem às formas efetivamente empregadas pelos falantes. Talvez por isso as formas apresentadas nessas sentenças possam parecer estranhas para alguns. Entre 
falantes escolarizados, porém, não há discussão quanto à gramaticalidade dessas sentenças. Portanto, os fatos parecem indicar que o verbo acreditar já foi capaz de selecionar small clauses complementos; contudo, perdeu essa possibilidade de seleção, pois não usamos mais construções como (25a). Uma conclusão definitiva sobre essa questão não será possível neste artigo, pois necessitamos de pesquisas que se voltem aos dados históricos do português. Não temos essa intenção aqui, mas queremos realçar que observamos esse mesmo comportamento em outros verbos como o crer e o reconhecer.

Verbo crer

(28) a.*O José crê a Maria inteligente.

b. * José crê a Maria.

c. *O José raramente crê as pessoas frequentemente inteligentes.

d. O José crê que Maria seja inteligente.

e. ? O José crê ser a Maria inteligente.

f.*O José crê Maria uma amiga.

O verbo crer não seleciona small clause complemento, como indicam as sentenças em (28). A única forma possível dentro dos testes que estamos utilizando é com a seleção de CP (José crê que Maria seja inteligente). Vejamos agora a forma pronominalizada da sentença (28a) em (29):

(29) O José a crê inteligente.

Se o sujeito da small clause aparece com pronome oblíquo, podemos então afirmar que o verbo crer seleciona small clause complemento. Contudo, novamente nos deparamos com uma sentença que não é mais encontrada no português.

Verbo reconhecer

(30) a. O júri reconheceu o réu culpado.

b.\#O júri reconheceu o réu.

c. O júri raramente reconheceu os réus constantemente culpados.

d. O júri reconheceu que o réu é culpado.

e. O júri reconheceu ser o réu culpado.

f. ? O júri reconheceu o réu um criminoso. 
O verbo reconhecer (sentido de declarar, admitir como legal) é capaz de selecionar small clause complemento, como revelam os testes de acarretamento (30b), dos advérbios (30c), da seleção de CP (30d) e de paráfrase com cópula (30e). No entanto, a sentença (30f), em que o verbo reconhecer seleciona uma small clause nominal, soa estranha para alguns falantes.

Queremos ressaltar que há, no português, muitas sentenças com o verbo reconhecer no sentido de (30) que não são interpretáveis: ??Maria reconhece Pedro inocente / ?Maria reconheceu a situação complicada / ??Reconheci Pedro inteligente. $\mathrm{O}$ verbo reconhecer prefere um CP: Maria reconhece que Pedro é inocente / Maria reconheceu que a situação era complicada / Reconheci que Pedro é inteligente. Esses dados indicam que a seleção de small clauses pelo verbo reconhecer já parece estar ocorrendo em contextos mais restritos. No entanto, na forma pronominalizada, sentenças como Maria o reconhece inocente são boas e são vestígios de que esse verbo pode selecionar small clause.

Concluímos que o verbo reconhecer ${ }^{11}$ ainda aceita a seleção de small clauses, já os verbos crer e acreditar parecem ter perdido essa possibilidade. Para uma conclusão precisa sobre esses últimos verbos, há necessidade de um estudo aprofundado que possa relatar por que não houve a esperada transição do oblíquo a/o pelo pessoal ele/ela. O pronome átono, no português do Brasil, é substituído pelo pronome ele/ela. Assim, esperávamos encontrar sentenças como ?Maria reconhece ele inteligente, contudo isso não acontece com os verbos reconhecer e com os outros verbos referidos (João crê ela inteligente / João acredita ela inocente). Fica aqui a sugestão para pesquisas futuras.

Obviamente, não queremos afirmar que os sujeitos das small clauses selecionadas pelos verbos anteriormente analisados, como considerar, julgar, declarar, não possam aparecer pronominalizados. Atribuímos destaque à forma pronominalizada somente nos verbos acreditar, crer e reconhecer porque, pelos testes apresentados, os dois primeiros verbos não se apresentaram capazes de selecionar small clause complemento. Tínhamos, porém, a intuição de que os verbos acreditar e crer podiam ser utilizados no sentido de considerar e também deviam selecionar small clause complemento, já que pertencem à mesma classe semântica. Precisávamos mostrar de que forma isso poderia ser possível. Já em relação ao verbo reconhecer, usamos a pronominalização como um argumento adicional. 
Enfim, os verbos que analisamos nesta seção são conhecidos na literatura como judicativos. Podemos relacionar semanticamente todos eles. Os verbos achar, declarar, julgar, acreditar, crer, reconhecer, quando estão selecionando small clauses complementos, apresentam um significado que pode ser equiparado ao considerar. Considerar pode ser entendido como julgar, ter na conta de, reputar. Os sentidos desses verbos estão entrelaçados, além de sua sintaxe. Mostramos aqui que uma característica desses verbos é a possibilidade de seleção de small clauses complementos, o que descarta a possibilidade de formarem estruturas de predicação secundária. Alguns deles, como acreditar, não selecionam small clause, mas mostram indícios de que já o fizeram.

\section{Considerações Finais}

Mostramos neste artigo que os complementos de certos verbos judicativos selecionam constituintes que são casos de predicação primária, sem flexão, ou seja, small clauses. Para tanto, apresentamos os testes de Rothstein (1995) que provam que o sujeito e o predicado das small clauses formam um único constituinte, ao contrário do que ocorre com os predicados secundários. Tal fato comprova que small clauses e predicados secundários têm estruturas diferentes. Com base nessas considerações, realizamos uma análise com os principais verbos judicativos do português com o objetivo de verificar quais deles podem selecionar small clauses complementos.

Entre os verbos analisados, concluímos que os verbos considerar, declarar, achar e julgar são exemplos típicos de verbos que selecionam small clauses complementos. Os verbos acreditar e crer sugerem que já foram capazes de selecionar, tanto que encontramos dados que revelam esses verbos selecionando small clauses, porém com a restrição de que o sujeito aparece sob a forma de pronome oblíquo - modo restrito, hoje, a registros formais. Testamos ainda os verbos reconhecer e supor que também indicam a possibilidade de seleção de small clauses complementos. 


\section{Notas}

${ }^{1}$ Agradecemos aos pareceristas anônimos desta revista, que muito contribuíram para as discussões aqui realizadas. Os problemas que ainda persistem são de nossa inteira responsabilidade.

${ }^{2} \mathrm{O}$ termo small clause recebeu traduções como minioração no Brasil ou oração pequena em Portugal. Neste artigo, preferimos usar o termo inglês por entendermos que já é uma nomenclatura internacional. As categorias utilizadas pela gramática gerativa também aparecerão aqui com os rótulos representando as expressões de língua inglesa, como $\mathrm{NP}$ (nominal phrase), VP (verbal phrase) e assim por diante. Vamos também pressupor do leitor o conhecimento das noções básicas implementadas pelo programa gerativista - não seria possível, no âmbito deste artigo, explicar cada uma delas.

${ }^{3} \mathrm{O}$ termo small clause envolve diferentes tipos de construções. Em vista disso, destacamos aqui a concepção que adotamos, bem como quais as estruturas compreendidas como small clause por esta teoria.

${ }^{4} \mathrm{Um}$ verbo inacusativo seleciona apenas argumento interno. Assim, o DP Maria que aparece na posição de sujeito não é argumento externo de parecer.

${ }^{5}$ Maiores detalhes a respeito de predicação secundária em Foltran (1999 e 2001).

${ }^{6}$ Não vamos entrar aqui no estatuto categorial da small clause, por ser esta uma discussão longa e complexa.

${ }^{7}$ Para discussão mais aprofundada a esse respeito, remetemos os leitores para Foltran \& Mioto (2007) e Mioto \& Foltran (2007).

${ }^{8} \mathrm{O}$ julgamento dos falantes varia com relação à aceitabilidade de (3). Há falantes que aceitam esse tipo de estrutura, ou seja, com a inclusão da cópula ser logo após o verbo da sentença matriz.

${ }^{9}$ Com a inclusão de dois advérbios em (5) obtemos a sentença Eu raramente considero Maria frequentemente inconveniente. Percebemos, entretanto, que nos casos em que o sujeito da small clause é indefinido (como em 6 - Eu raramente considero as pessoas frequentemente inconvenientes) é mais fácil verificar a aceitabilidade de sentenças com dois advérbios. Do mesmo modo, complementos plurais parecem favorecer essa inclusão (Meu pai raramente considera minhas irmãs frequentemente responsáveis). Assim, a indefinitude e, talvez, a pluralidade torna as sentenças com dois advérbios mais aceitáveis.

${ }^{10}$ É importante observar que é obrigatoriamente a cópula ser a permitida nesse tipo de estrutura. Isso tem a ver com o caráter de propriedade permanente (ou individual level). Mais informações a esse respeito em Foltran (1999). 
${ }^{11}$ Por isso consideramos que o teste de inserção de DP não tenha sido definitivo neste caso. Como o julgamento dos falantes varia com relação à (30f), acreditamos que isso pode ocorrer devido ao fato de que reconhecer parece estar sendo cada vez menos usado no sentido em (30).

\section{Referências}

CHOMSKY, N. Lectures on government and binding. Dordrecht: Foris, 1981.

FOLTRAN, M. J. As construções de predicação secundária no português do Brasil: aspectos sintáticos e semânticos. 1999. Tese (Doutorado) - Universidade de São Paulo, São Paulo, 1999.

FOLTRAN, M. J. Predicados complexos. Revista Letras. Curitiba, n.53, p. $127-$ 139, 2001.

FOLTRAN, M. J.; MIOTO, C. As small clauses revisitadas: apresentação. Cadernos de Estudos Linguísticos, v. 49, n.1, Campinas: Editora da Unicamp, p. 5-9, 2007. KAYNE, R. Connectedness and binary branching. Dordrecht: Foris, 1984.

MIOTO, C.; FOLTRAN, M. J. A favor de small clauses. Cadernos de Estudos Linguísticos, v. 49, n.1, Campinas: Editora da Unicamp, p.11-28, 2007.

ROTHSTEIN, S. Small Clauses e Copular Constructions. In: CARDINALETTI, A.; GUASTI, M. T. Sintax e Semantics: Small Clauses. Califórnia, v. 28, p. 27-48, 1995.

ROTHSTEIN, S. Predicates and their Subjects. Dordrecht: Kluwer Academic Publishers, 2001.

SCHEIN, B. Small Clauses and Predication. In: CARDINALETTI, A.; GUASTI, M. T. Sintax e Semantics: Small Clauses. Califórnia, v. 28, p. 49-76, 1995.

STOWELL, T. Subjects across categories. The Linguistic Review 2, p. 285-312, 1983. 